\title{
Selective Oxidation of Methane over Vycor Glass, Quartz Glass and Various Silica, Magnesia and Alumina Surfaces
}

\author{
G.N. KASTANAS*, G.A. TSIGDINOS and I. SCHWANK \\ Department of Chemical Engineering, The University of Michigan, Ann Arbor, Michigan \\ 48109-2136 (U.S.A.)
}

(Received 23 December 1987, revised manuscript received 8 July 1988)

\begin{abstract}
The reaction between methane and oxygen was investigated in empty Vycor glass and quartz tubes and over various silica compounds in powder form. In the temperature range of 893-993 K and with methane-to-oxygen ratios close to unity, formaldehyde, ethane and ethene were produced with a combined 53-96\% selectivity over Vycor glass reactor surfaces. Quartz reactor surfaces were less active, but gave the same products. Silica compounds in powder form such as Cab-O-Sil, Ludox gels and silicic acid were investigated at temperatures lower than $893 \mathrm{~K}$ where the blank activity of the quartz reactor became negligible. These silica compounds followed similar trends of activity as the Vycor or quartz reactor tubes, although at much lower temperalures. High oxygen-to-methane ratios improved the rates of overall methane reaction and $\mathrm{C}_{2}$ formation. Short residence times enhanced the formaldehyde over the carbon monoxide and carbon dioxide selectivity. The reaction rates increased with pressure. However, in contrast to the results on empty reactor surfaces, no ethane was produced over the silica compounds, the ethene yields were lower, and the carbon dioxide production was higher. While the apparent activation energies for the overall methane reaction and for the production of carbon monoxide, carbon dioxide, ethene and ethane were dependent on the nature of the catalytic surface, the apparent activation energy for the formaldehyde formation appeared to be independent of the catalyst and remained constant at about $130 \mathrm{~kJ} / \mathrm{mol}$. This might imply that formaldehyde is generated in the gas phase and that carbon monoxide and carbon dioxide can be formed in secondary reactions of formaldehyde involving surface interactions. The effect of the acid/base character of the catalyst was explored by comparing the activities of the silica compounds with those of $\mathrm{MgO}$ and $\gamma-\mathrm{Al}_{2} \mathrm{O}_{3} . \mathrm{MgO}$ and $\gamma-\mathrm{Al}_{2} \mathrm{O}_{3}$ were more active than the silicas, but produced only carbon monoxide and carbon dioxide.
\end{abstract}

\section{INTRODUCTION}

The conversion of methane or natural gas into useful intermediate oxidation products instead of complete oxidation to carbon dioxide or partial oxidation to carbon monoxide is one of the most challenging problems for catalysis research [1]. The relative inertness of the methane molecule towards the activation of its $\mathrm{C}-\mathrm{H}$ bonds and the tendency for complete dissociation once 
activation is achieved are the main obstacles that need to be overcome. To date no commercial catalytic process exists that would yield useful higher hydrocarbons or oxygenates from methane in high activities and selectivities. Currently the research on selective oxidation of methane is gaining more and more importance [2] and most of the efforts are concentrated towards the production of ethane and ethene via oxidative dimerization of methane [3-9].

Oxidative dimerization is achieved at high temperatures, usually within the range of $923 \mathrm{~K}$ to $1123 \mathrm{~K}$. Ito et al. [4] used lithium doped $\mathrm{MgO}$ with nitrous oxide as an oxidant. They attributed the activity towards $\mathrm{C}_{2}$ products to the generation of $\mathrm{O}^{-}$surface species, which are capable of abstracting hydrogen from methane and forming $\mathrm{CH}_{3} \cdot$ radicals. The subsequent recombination of the $\mathrm{CH}_{3} \cdot$ radicals leads to ethane or ethene formation. Otsuka et al. [5] showed that $\mathrm{Sm}_{2} \mathrm{O}_{3}$ is a very promising candidate for the oxidative dimerization of methane and lately the lanthanides seem to gain more importance as catalysts for this particular reaction $[5,6]$. The $\mathrm{Mn}_{2} \mathrm{O}_{3} / \mathrm{Mn}_{3} \mathrm{O}_{4}$ system was the most promising from a large number of reducible oxides $[7,8]$. Catalysts based on $\mathrm{Bi}_{2} \mathrm{O}_{3}$ showed high activity but low selectivity towards $\mathrm{C}_{2}[9]$.

In the high temperatures used for the oxidative dimerization, gas phase oxidation of methane is very likely to occur [10]. Wall effects [3] can account for part of the conversion. Their contribution, however, has not been fully investigated.

Only a relative small number of investigations have focused on the selective oxidation of methane to oxygenates such as formaldehyde and methanol. Formaldehyde is a very important starting material for the production of resins and polymers [11]. Currently, half of all methanol produced is used for the manufacture of formaldehyde [12]. Methanol is also used as an octane improver and gasoline substitute. Recently it has found application as feedstock for gasoline production in the Mobil MTG (Methanol-to-Gasoline) process which is commercially operated in New Zealand with ZSM-5 zeolite as catalyst [13].

By using nitrous oxide as an oxidant Liu et al. [14] reported the formation of formaldehyde and methanol from methane over a $\mathrm{Mo} / \mathrm{SiO}_{2}$ catalyst. The activation of methane was attributed to the presence of $\mathrm{O}^{-}$species on the catalyst surface that initiate the reaction by generating $\mathrm{CH}_{3}$.radicals. Although the reaction temperature of $873 \mathrm{~K}$ was lower than in the oxidative dimerization reactions [3-9] it was found necessary to replace the catalyst after each run, because of metal loss. The results of Liu et al. were reproduced by Khan and Somorjai [15] and a detailed kinetic study was performed. Gesser et al. in a recent patent [16] claim that direct conversion of natural gas to methanol can be achieved by a gas phase oxidation at $573-773 \mathrm{~K}$ and pressures of 1000 to $10000 \mathrm{kPa}$.

Antonik and Lucquin [17] and Antonik [18] studied the mechanism of the gas phase oxidation of methane and the roles of formaldehyde and methanol 
as important reaction intermediates. Hydrogen bromide and chlorine were used as promoters. Kegeyan et al. $[19,20]$ report the production of methanol and organic peroxides from the oxidation of methane at $673-773 \mathrm{~K}$ in a reactor vessel which was pretreated in a boric acid solution. It was concluded that peroxy radicals played an important role in the formation of methanol. McConkey and Wilkinson [21] investigated the oxidation of methane to formaldehyde in presence of homogeneous initiators such as $\mathrm{NO}, \mathrm{HBr}$, and $\mathrm{HCl}$ by using $\mathrm{SiO}_{2}$ and $\mathrm{Al}_{2} \mathrm{O}_{3}$ based catalysts at high temperatures $(943 \mathrm{~K})$. It was found that the residence time had a very important effect on the selectivity. With increasing conversion, the selectivity decreased.

The general conclusion from the above is that gas-phase reactions and wall and reactor geometry effects may contribute to the selective oxidation activity. Therefore, they should be taken into consideration in the studies of selective oxidation of methane.

In the first part of this work, the effect of glass surfaces such as Vycor brand and quartz on methane activation and the factors that favor the production of formaldehyde are investigated. Vycor glass has been proven to be active at room temperature in the $\mathrm{n}$-butene isomerization, as demonstrated by the work of Little et al. [22] as well as in the adsorption of ammonia at $150^{\circ} \mathrm{C}$ as shown by Cant and Little [23]. It was generally believed that the surface hydroxyl groups played an important role in the adsorption, being capable of forming hydrogen bonds with the adsorbate. This was further demonstrated in the work of Folman and Yates [24] where a contraction of Vycor glass was measured as a result of the adsorption of various molecules. The glass contraction was attributed to the attraction forces of the formed $\mathrm{H}$-bonds. The perturbance of the surface hydroxyl groups as a result of adsorption is well known for $\mathrm{SiO}_{2}$, as reported by Little [25]. Sheppard and Yates studied the interaction of various molecules with Vycor glass by IR spectroscopy [26]. In the case of methane a new band, not present in the gas phase spectrum appeared, and it was attributed to physical adsorption. Cheaney and Walsh [27] observed a high activity of Vycor glass tubes in the combustion of methane. They attributed the activity to the deposition of a silicic acid layer on the glass surface during the manufacture of the Vycor glass which included a treatment with hydrogen fluoride. When silica tubes were coated with silicic acid, the high methane combustion activity of the Vycor tubes could be reproduced [27]. Grabowski [28] showed by theoretical calculations that an interaction between the methane molecule and the silica surface is possible.

In the second part various forms of $\mathrm{SiO}_{2}$ such as silicic acid, Cabosil fumed silica, and silica gels prepared from Ludox colloidal silica are tested for their ability to activate methane. The apparent activation energies for the various products of the selective oxidation of methane over silicic acid are determined and catalyst deactivation is studied.

Finally in the third part other catalytic materials besides silica, namely $\mathrm{MgO}$ 
and $\mathrm{Al}_{2} \mathrm{O}_{3}$ are studied in an attempt to assess the effect of the acidity on the activity and selectivity of methane oxidation.

\section{EXPERIMENTAL}

\section{Flow system and product analysis}

A flow reactor system was used with on-line analysis of the products, as described elsewhere [29]. The system lines except for the reactor were made of Teflon-coated stainless steel, SS-316. The reactor consisted of a U-tube with $4 \mathrm{~mm}$ inside diameter and $1 \mathrm{~mm}$ wall thickness made out of either Vycor glass or quartz. Cajon fittings were used to connect the U-tube to the stainless steel lines. The catalyst was positioned at the bottom of the $\mathrm{U}$-tubes with the help of glasswool plugs made out of Pyrex or quartz wool, depending on the reaction temperature. The reactor outlct lines were heated in order to avoid condensation.

The U-tube was placed in an oven whose temperature was controlled to \pm 1 $\mathrm{K}$ by an Omega $4002 \mathrm{KC}$ controller. The total volume of the heated part of the reactor was approximately $3 \mathrm{~cm}^{3}$ with the catalyst and the glasswool plugs occupying approximately one third of this volume. A thermocouple was placed in direct contact with the outside surface of the U-tube next to the catalyst bed, in order to avoid any potential contribution of the thermocouple material to the reaction. Tests were made with thermocouple wires placed on the outside surface as well as inside the $U$-tube. At any reaction temperature, the maximum discrepancy observed was $3-5 \mathrm{~K}$. The pressure in the range of 170 to 660 $\mathrm{kPa}$ was regulated by a needle valve in the reactor outlet. 'The gas flow was controlled by digital mass flow controllers (Tylan FC-260).

On line-analysis of the reaction products was performed using a Varian 3700 gas chromatograph equipped with both thermal conductivity and flame ionization detectors in series. Data acquisition and analysis was performed by a Varian 4270 integrator that controlled the automatic sampling and column switching valves.

The product gases first eluted through a $1.8-\mathrm{m}$ Porapak QS column at 333 $\mathrm{K}$ with helium carrier gas flowing at a rate of $0.5 \mathrm{~cm}^{3} / \mathrm{s}$. The permanent gases eluted very quickly and were passed into a molecular sieve column $(0.9 \mathrm{~m}, 5 \mathrm{~A})$ where they were trapped. A switching valve was then actuated on time for the elution from the Porapak column of carbon dioxide, ethene and ethane which were passed through the detector. By switching back to the molecular sieve column the permanent gases with low retention time $\left(\mathrm{O}_{2}, \mathrm{~N}_{2}, \mathrm{CH}_{4}\right.$ and $\left.\mathrm{CO}\right)$ were now eluted into the detector. One more switch to bypass the molecular sieve column and simultaneous increase of the Porapak column temperature from $333 \mathrm{~K}$ to $463 \mathrm{~K}$ allowed for the analysis of oxygenates and hydrocarbons. After the end of the run the column temperature was brought back to $333 \mathrm{~K}$ 
and the valve was switched back to the molecular sieve column, making the system ready for the next injection.

For the positive identification of formaldehyde and other oxygenates, a combination of gas chromatography and mass spectrometry (GC-MS) was used. The reactor effluent was first passed through a Porapak QS column and then through a mass spectrometer (Finnigan GC/MS).

A dilute mixture of $10 \%$ methane in $\Lambda$ rgon (Air Products) was used. The purity of the methane was $>99 \%$ and the purity of argon was $99.998 \%$. Analysis of the methane gas revealed traces of ethane at a level of 0.14 vol.- $\%$. Extra dry, high purity ( $>99.6 \%$ ) oxygen (Metro Welding) was used.

Prior to admitting methane to the reactor, a flow of oxygen at a flow-rate of $20-30 \mathrm{~cm}^{3} \mathrm{STP} / \mathrm{min}$ was established and the temperature of the reaction zone was raised to $993 \mathrm{~K}$ for runs with empty reactor tubes, and to $893 \mathrm{~K}$ for runs in presence of a catalyst bed. After sustaining this oxygen flow for about $2 \mathrm{~h}$, the oxygen flow-rate and temperature were brought to the desired level for the reaction with methane. The argon-methane flow was then turned on and 10$15 \mathrm{~min}$ later the first sample of products was taken. Several data points were collected at each temperature over a period of about $6 \mathrm{~h}$. As it will be shown later no serious deactivation problems were encountered.

The methane conversion was determined from the amount of reaction products formed as quantified by the GC analysis. The amount of methane in the reactor feed was determined from GC runs in which the reactor was bypassed. The percent methane conversion $x_{i}$ to a given product $i$ was then calculated as shown in eqn. (1):

$x_{i}=\left[100 \cdot\left(\mathrm{mol} \mathrm{CH}_{4} \mathrm{~s}^{-1}\right.\right.$ converted to product $\left.\left.i\right)\right] /\left(\mathrm{mol} \mathrm{CH}_{4} \mathrm{~s}^{-1}\right.$ in feed $)$

The total conversion of methane, $x_{i}$, was determined by summation of all the individual product conversions $x_{i}$. The percent selectivity $S_{i}$ towards a specific product $i$ was calculated as follows:

$S_{i}=100 x_{i} / x_{t}$

As a test for coking, a material balance was performed as follows: the calculated total amount of converted methane was subtracted from the experimentally determined amount of methane in the reactor feed. The result was compared with the amount of methane in the reactor effluent as experimentally determined by GC analysis. At the low conversion levels used throughout this work, the amount of coke formed was of the order of magnitude of the experimental error in determining the conversion. Furthermore, no visible signs of coking, such as discoloration, were noticeable in the used catalysts.

The rate of formation of a specific product was calculated from the conversion of methane to that product. The overall rate of reaction of methane was 
determined from its total conversion to products. The following expressions were used:

$r_{i}=F_{\mathrm{M}} \cdot x_{i} / 100 \cdot W$

$r_{t}=F_{\mathrm{M}} \cdot x_{t} / 100 \cdot W$

where $r_{i}$ is the rate of formation of a product $i$ per $g$ of catalyst and $\mathrm{s}, r_{t}$ the overall rate of methane consumption per $\mathrm{g}$ of catalyst and $\mathrm{s}, F_{\mathrm{M}}$ the flow-rate of methane in mol/s, and $W$ the catalyst weight in $g$. Normalization of reaction rates in terms of turnover frequencies did not appear practical, since there is good reason to believe that homogeneous gas-phase reactions and/or reactions on the reactor walls may contribute to some of the product formation. In the case of empty reactor tubes, the reaction rates were normalized per $\mathrm{m}^{2}$ of inner surface of the tubes calculated from the tube geometry. For the empty glass tubes the residence time $\tau$ was determined as follows:

$\tau=V_{\mathrm{R}} / F_{t}[\mathrm{~s}]$

where $V_{\mathrm{R}}$ represents the volume of the heated reactor zone in $\mathrm{cm}^{3}$, and $F_{t}$ the total gas flow-rate in $\mathrm{cm}^{3} / \mathrm{s}$. For the catalytic runs the residence time $\tau$ was determined as shown in eqn. (6):

$\tau=W / F_{t}\left[\mathrm{~g} \cdot \mathrm{s} / \mathrm{cm}^{3}\right]$

\section{Materials}

Vycor brand glass is made by a process developed by the Corning corporation in which an alkali-borosilicate glass is heat treated and leached with acid, resulting in the formation of a porous glass of very high silica content (96\%) [30]. Quartz glass from Wale Apparatus Co. was used. All the runs with catalyst beds were performed in quartz U-tubes.

Fumed silica (Cab-O-Sil) made by the Cabot corporation was pelletized prior to loading into the reactor. The silicic acid was Mallinckrodt analytical reagent grade with very low impurity concentration and a surface area of $275 \mathrm{~m}^{2} / \mathrm{g}$. It was used as received in powder form.

In the preparation of silica gels, Ludox colloidal silica solutions (Dupont) were employed. Ammonium stabilized AS-40 solution ( $\mathrm{pH} \mathrm{9)}$ was used, acidified with a small amount of nitric acid (70\% weight, Baker reagent) and heated to $368 \mathrm{~K}$ where it gelled. The final $\mathrm{pH}$ before gelation fell to about 6 . The gel was dried at room temperature for one day and then calcined at $923 \mathrm{~K}$ for $6 \mathrm{~h}$. The surface area was $110 \mathrm{~m}^{2} / \mathrm{g}$. The Ludox gel contained besides $\mathrm{SiO}_{2}$ $0.38 \%$ by weight of $\mathrm{Na}_{2} \mathrm{O}, 0.002 \%$ of chloride and $0.005 \%$ of sulfate anions.

Apart from the silica compounds the following catalysts were used: $\mathrm{MgO}$ (Carlo Erba RPE-ACS, prepared from reagent grade magnesium carbonate 
and calcined at $1273 \mathrm{~K}$, surface area of $47 \mathrm{~m}^{2} / \mathrm{g}$ ), and very high purity $\gamma-\mathrm{Al}_{2} \mathrm{O}_{3}$ from Strem Chemicals (surface area of $120 \mathrm{~m}^{2} / \mathrm{g}$ ). These BET surface areas were determined after use of the materials under methane oxidation reaction conditions.

\section{RESULTS AND DISCUSSION}

\section{Activity of Vycor-Quartz reactor tubes}

Table 1 summarizes the total conversion of methane, $x_{t}$, and the selectivities $S_{i}$ of the various products obtained in our quartz and Vycor glass tubes. At a methane-to-oxygen molar ratio of about 1 and over the temperature range of 893 to $993 \mathrm{~K}$ both tube surfaces produced ethene, ethane, formaldehyde and carbon dioxide. Under the reaction conditions used here, carbon monoxide was observed only over Vycor glass at temperatures $>940 \mathrm{~K}$. The carbon monoxide production occurred mainly at the expense of formaldehyde. As we will see later, carbon monoxide production can be achieved even over quartz by increasing the residence time. At a given temperature, the total methane conversion, $x_{t}$, over Vycor glass was much higher than the one over quartz. At similar conversion $(0.41 \%$ at $928 \mathrm{~K}$ for Vycor glass and $0.37 \%$ at $993 \mathrm{~K}$ for quartz) the carbon dioxide selectivity over Vycor glass was much lower than te one observed over quartz whereas the formaldehyde selectivity was somewhat higher. The very substantial differences in activity and selectivity be-

\section{TABLE 1}

Conversion and selectivity achieved over Vycor and quartz U-tubes at a methane-to-oxygen ratio of 1.14

Flow-rates: $10 \%$ methane in argon $=29.7 \mathrm{~cm}^{3} \mathrm{STP} / \mathrm{min}$, oxyen $=2.6 \mathrm{~cm}^{3} \mathrm{STP} / \mathrm{min} . p=205$ $\mathrm{kPa}$

\begin{tabular}{llllllll}
\hline & \multirow{2}{*}{$\begin{array}{l}\text { Temperature } \\
(\mathrm{K})\end{array}$} & $x_{f}(\%)$ & \multicolumn{2}{l}{$S_{i}(\%)$} & & & \\
\cline { 5 - 8 } & & & $\mathrm{C}_{2} \mathrm{H}_{4}$ & $\mathrm{C}_{2} \mathrm{H}_{6}$ & HCHO & $\mathrm{CO}$ & $\mathrm{CO}_{2}$ \\
\hline \multirow{2}{*}{ Vycor } & 893 & 0.26 & 2 & 15 & 81 & - & 2 \\
& 913 & 0.31 & 3 & 13 & 81 & - & 3 \\
& 928 & 0.41 & 4 & 17 & 76 & - & 3 \\
& 943 & 0.95 & 4 & 12 & 44 & 35 & 5 \\
& 958 & 1.44 & 4 & 15 & 40 & 37 & 4 \\
& 973 & 2.26 & 5 & 17 & 34 & 41 & 3 \\
& 993 & 3.93 & 7 & 19 & 27 & 45 & 2 \\
Quartz & 963 & & & & & & \\
& 993 & 0.13 & 8 & 13 & 62 & - & 17 \\
& & 0.37 & 9 & 18 & 60 & - & 13 \\
\hline
\end{tabular}


tween Vycor and quartz reactors despite identical flow conditions and reactor geometries imply that gas interactions sensitive to the nature of the tube surfaces occur. However, in view of the high temperatures, a contribution of gas phase reactions cannot be ruled out.

The residence time $\tau$ has a very significant effect on the product distribution. Fig. 1 illustrates this effect for a quartz reactor at $993 \mathrm{~K}$ where $\tau$ was increased from $3.3 \mathrm{~s}$ to $13.2 \mathrm{~s}$ by reducing the flow-rates by a factor of four while keeping the methane-to-oxygen ratio close to 1 . The total methane conversion increased from $0.3 \%$ to $2.52 \%$. At $\tau=3.3 \mathrm{~s}$ the formaldehyde selectivity was $60 \%$ and the combined ethene and ethane selectivity was $27 \%$. The remaining $13 \%$ consisted of carbon dioxide. The short residence time quartz runs did not produce any carbon monoxide. At the long residence time run of $13.2 \mathrm{~s}$ carbon monoxide was generated at the expense primarily of formaldehyde. This implies that long residence times increase the probability of carbon monoxide formation via the decomposition of formaldehyde, a reaction sequence analogous to that observed in the combustion of methane [10]. Therefore, operation

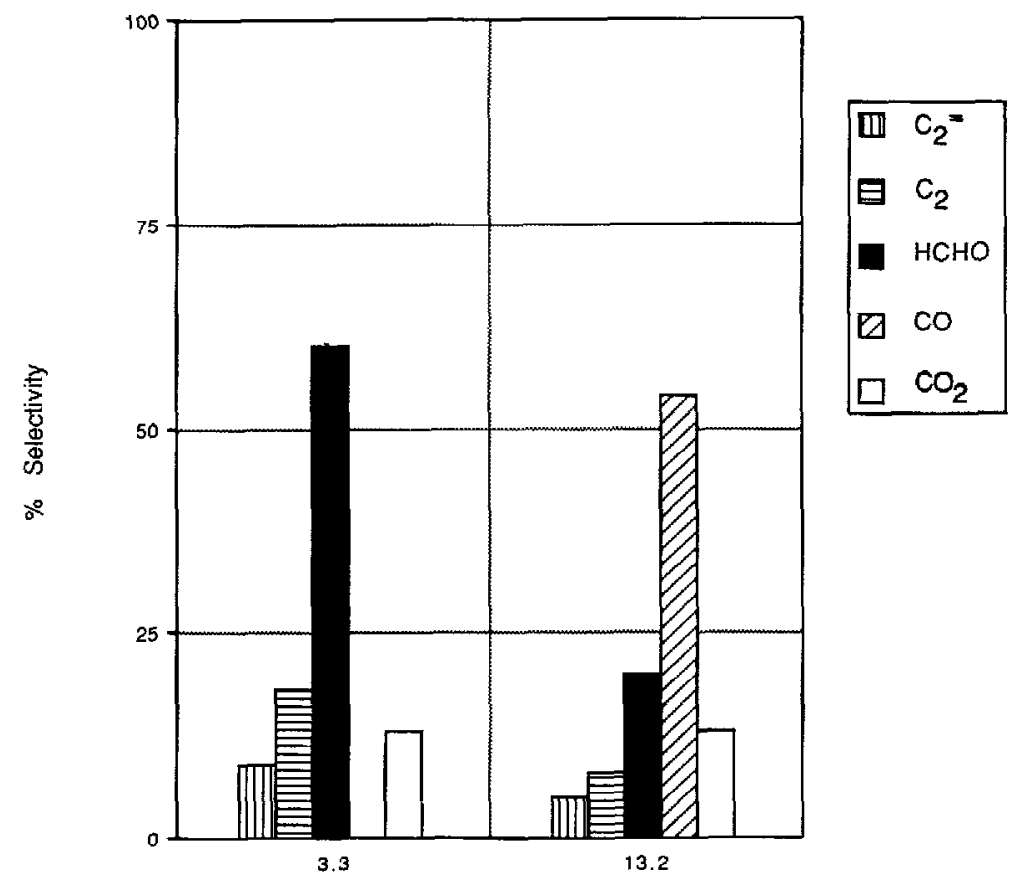

Residence time [s]

Fig. 1. Methane oxidation over empty quartz reactors. Effect of the residence time on the product distribution at $993 \mathrm{~K}$ and methane-to-oxygen ratio close to 1. 
at low residence times favors the formaldehyde formation. Similar residence time effects were observed in the Vycor reactors.

In another experiment, the heated part of the quartz reactor was filled with quartz chips. Under identical conditions of methane and oxygen flow, pressure and temperature it was found that the activity was lower than the one of the empty tube by an order of magnitude.

These results clearly demonstrate the contribution of the gas phase in the propagation of the methane oxidation reaction.

The methane-to-oxygen ratio is another important factor influencing the product distribution. The methane-to-oxygen ratio was varied by keeping the methane flow-rate constant and varying the oxygen flow-rates. As shown in Fig. 2 for Vycor reactors at $943 \mathrm{~K}$, a decrease of the methane-to-oxygen ratio from 0.998 to 0.494 doubled the rates of formation of formaldehyde, ethene and ethane. Further decrease of the methane-to-oxygen ratio to 0.21 enhanced the production of ethene and ethane. However, the yield of formaldehyde was now

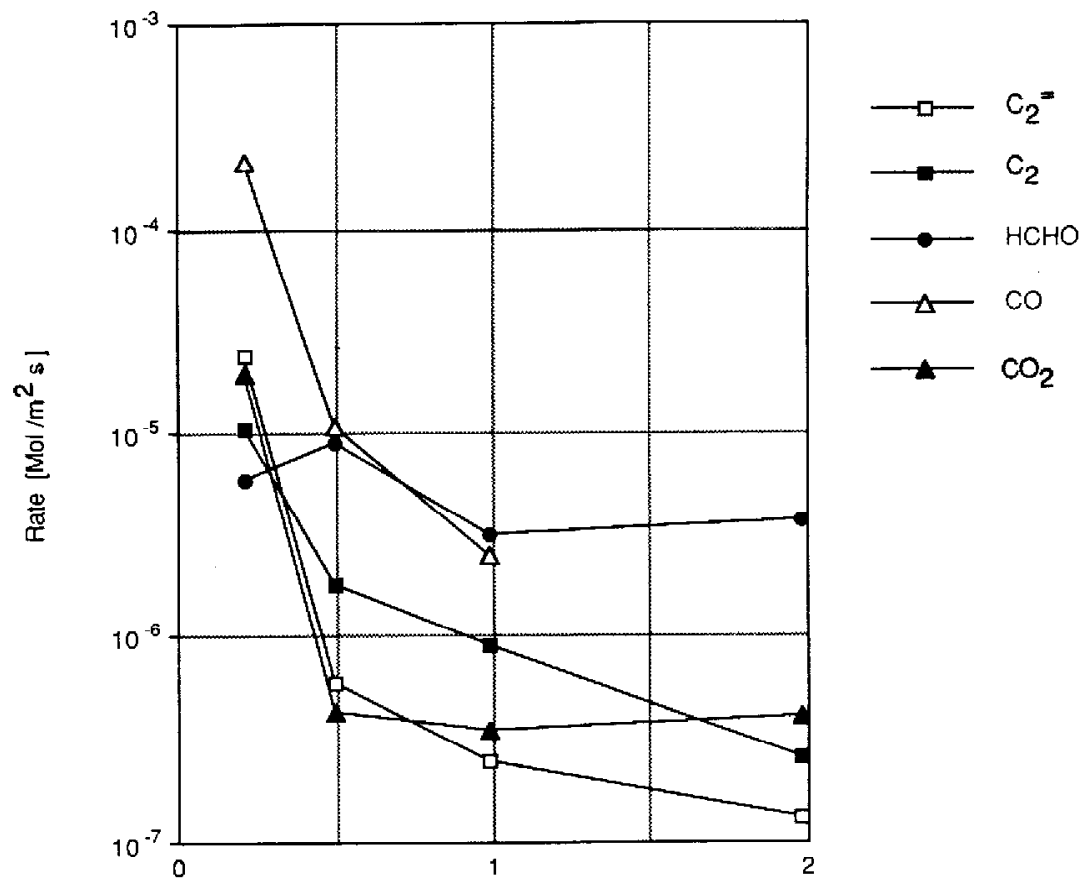

$\mathrm{CH} 4 / \mathrm{O} 2$ Ratio

Fig. 2. Effect of the methane-to-oxygen ratio on the product distribution obtained in empty Vycor glass reactors at $943 \mathrm{~K}$. Flow rates: $10 \%$ methane in argon $=29.7 \mathrm{~cm}^{3} \mathrm{STP} / \mathrm{min}$, oxygen from 1.5 to $14 \mathrm{~cm}^{3} \mathrm{STP} / \mathrm{min} . p=205 \mathrm{kPa}$. 
lower due to the oxidation of formaldehyde to carbon monoxide and carbon dioxide. On the other hand, an increase of the methane-to-oxygen ratio to 1.98 led to lower formation rates of ethene and ethane, a slight increase of the formaldehyde rate and a complete disappearance of the carbon monoxide.

In view of the blank activity of the quartz, an upper temperature limit of 893 $\mathrm{K}$ was imposed on runs with catalyst powders placed into quartz reactors. Up to this temperature, the glasswool used to retain the catalysts in the U-tubes did not have any measurable effect on the blank activity of the quartz reactors.

Activity of silica based compounds

Various silica based compounds in powder form, including silicic acid, Cab$\mathrm{O}$-Sil, and Ludox gel exhibited similar trends of methane conversion as the empty Vycor and quartz reactors, although at much lower temperatures. Methane-to-oxygen ratios lower than one enhanced the activity of these catalysts, in accordance with the behaviour in the Vycor brand and quartz tubes. Short residence times favored the selectivity of formaldehyde, as shown on Fig. 3 for Cab-O-Sil at a methane-to-oxygen ratio close to 1 and a temperature of $893 \mathrm{~K}$.

Similar behavior was observed on the silicic acid and Ludox gel samples. Consequently, one way to improve the formaldehyde selectivity would be to use high flow-rates and low residence times. Table 2 shows the conversion and selectivity values obtained over silicic acid, which proved to be very active on a weight basis.

By comparison of the results of Tables 1 and 2 it is clear that silicic acid gives the same methane conversion as Vycor glass at temperatures as much as 100 $\mathrm{K}$ lower. However, there is a substantial difference in the ethane and ethene selectivities. No ethane is produced over silicic acid and the selectivity of ethene is lower than the one of the Vycor tubes ( $1 \%$ versus $5-7 \%$ at comparable conversions). Moreover the carbon dioxide selectivity of the silicic acid catalysts is higher than the one of the Vycor tubes ( $10 \%$ versus $3 \%$ at comparable conversions). As a conclusion, at comparable conversions the surface of silicic acid is more likely to produce carbon dioxide than the Vycor glass surface. This appears to be primarily achieved at the expense of the $\mathrm{C}_{2}$ products which are more susceptible to oxidation than methane.

Table 3 compares the overall rate of methane reaction and the selectivity over the various silica compounds for a methane-to-oxygen ratio of close to 1 at a temperature of $893 \mathrm{~K}$. The rate of reaction is reported in two different ways, based on the weight and the surface area of the catalysts as determined after the reaction.

All three catalysts produced methane, formaldehyde, carbon monoxide and carbon dioxide. From the silicic acid runs, a trend emerged of increasing rate of methane reaction with increasing pressure. Blank runs performed over empty quartz reactors at higher pressures up to $450 \mathrm{kPa}$ also showed some increase 


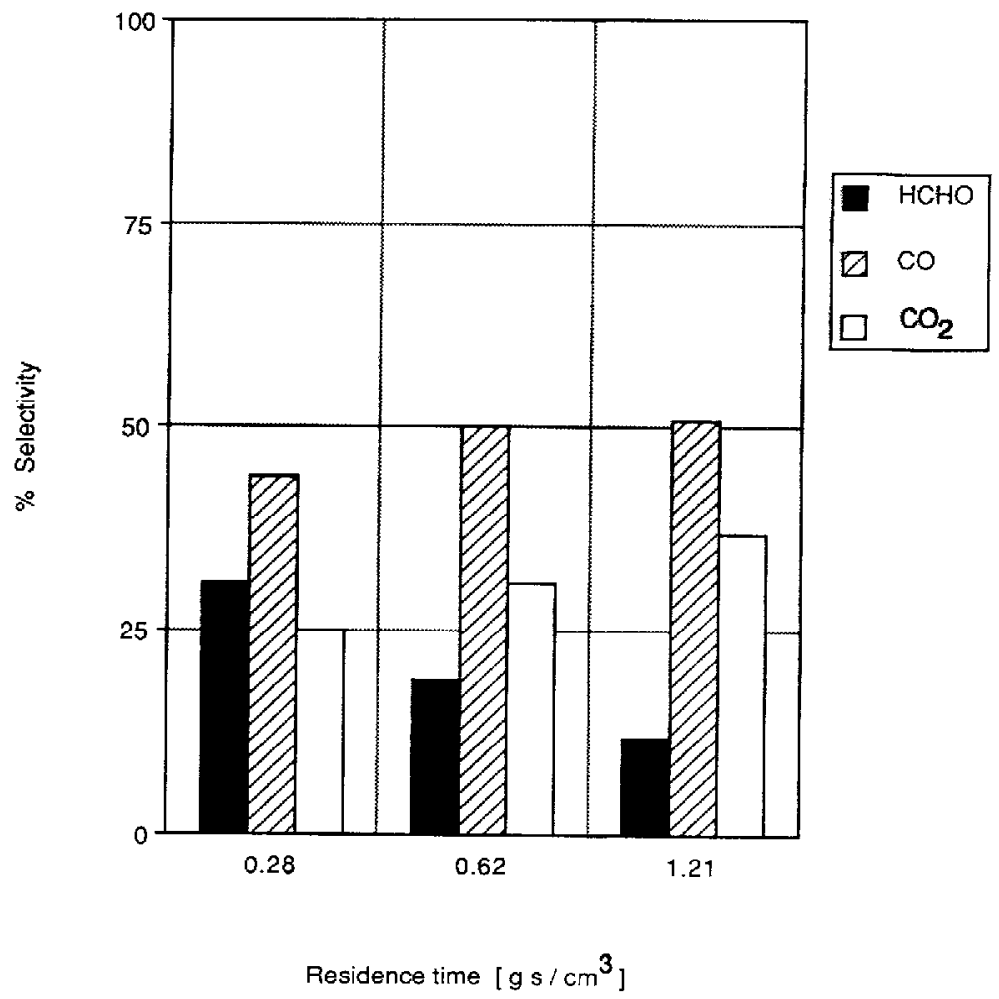

Fig. 3. Methane oxidation over Cab-O-Sil silica. Effect of the residence time on the product distribution at $893 \mathrm{~K}$ and methane-to-oxygen ratio close to 1 .

\section{TABLE 2}

Conversion and selectivity achieved over silicic acid at a methane-to-oxygen ratio of 1.14

Flow-rates in $\mathrm{cm}^{3} \mathrm{STP} / \mathrm{min}: 10 \%$ methane in argon $=29.7$, oxygen $=2.6 . p=218 \mathrm{kPa}$. Catalyst weight $W=0.553 \mathrm{~g}$

\begin{tabular}{lllllr}
\hline $\begin{array}{l}\text { Temperature } \\
(\mathrm{K})\end{array}$ & $\begin{array}{l}x_{t}(\%) \\
\text { conversion }\end{array}$ & \multicolumn{2}{l}{$S_{i}(\%)$} & & \\
\cline { 2 - 5 } & & $\mathrm{C}_{2} \mathrm{H}_{\mathbf{4}}$ & $\mathrm{HCHO}$ & $\mathrm{CO}$ & $\mathrm{CO}_{2}$ \\
\hline 853 & 1.4 & 1 & 48 & 38 & 13 \\
868 & 3.0 & 1 & 31 & 59 & 9 \\
893 & 4.8 & 1 & 24 & 65 & 10 \\
\hline
\end{tabular}

in activity as a function of pressure, however, the activity remained lower than the one of the silicic acid by more than an order of magnitude. The effect of pressure is currently being investigated in more detail and will be a subject for 
TABLE 3

Activity and selectivity of various silica compounds at $893 \mathrm{~K}$ and a methane-to-oxygen ratio close to 1

\begin{tabular}{|c|c|c|c|c|c|c|c|c|}
\hline \multirow[t]{2}{*}{ Compound } & \multirow{2}{*}{$\begin{array}{l}\text { Pressure } \\
(\mathrm{kPa})\end{array}$} & \multirow{2}{*}{$\begin{array}{l}\text { Overall } \\
\text { methane } \\
\text { reaction rate } \\
\text { (mol/gs) }\end{array}$} & \multirow{2}{*}{$\begin{array}{l}\text { Overall methane } \\
\text { reaction rate } \\
\left(\mathrm{mol} / \mathrm{m}^{2} \mathrm{~s}\right)\end{array}$} & \multirow{2}{*}{$\begin{array}{l}\text { Surface area } \\
\text { after reaction } \\
\left(\mathrm{m}^{2} / \mathrm{g}\right)\end{array}$} & \multicolumn{4}{|c|}{$S_{i}(\%)$} \\
\hline & & & & & $\mathrm{C}_{2} \mathrm{H}_{4}$ & $\mathrm{HCHO}$ & $\mathrm{CO}$ & $\mathrm{CO}_{2}$ \\
\hline \multirow[t]{3}{*}{ Silicic acid } & $218^{\star}$ & $1.98 \mathrm{E}-7^{\star \star \star}$ & $0.72 E-9$ & 274 & 1 & 23 & 66 & 10 \\
\hline & $340^{\star \star}$ & $2.6 \mathrm{E}-7$ & $0.95 \mathrm{E}-9$ & 274 & 7 & 47 & 37 & 9 \\
\hline & $515^{* *}$ & $4.2 \mathrm{E}-7$ & $1.53 \mathrm{E}-9$ & 274 & 1 & 26 & 62 & 11 \\
\hline Cab-OSil & $308^{\star \star}$ & $2.75 \mathrm{E}-7$ & $1.44 \mathrm{E}-9$ & 191 & 1 & 30 & 45 & 24 \\
\hline Ludox gel & $377^{\star \star}$ & $0.9 \mathrm{E}-7$ & $0.87 \mathrm{E}-9$ & 105 & 1 & 27 & 67 & 5 \\
\hline
\end{tabular}

* Flow-rates: $10 \%$ methane in argon $=29.7 \mathrm{~cm}$. STP $/ \mathrm{min}$, oxygen $=2.6 \mathrm{~cm}^{3} \mathrm{STP} / \mathrm{min}$.

${ }^{\star *}$ Flow-rates: $10 \%$ methane in argon $=46.8 \mathrm{~cm}^{*} \mathrm{STP} / \mathrm{min}$, oxygen $=5.2 \mathrm{~cm}^{33} \mathrm{STP} / \mathrm{min}$.

${ }^{\star \star \star} 1.98 \mathrm{E}-7$ corresponds to $1.98 \cdot 10^{-\bar{*}}$.

future publication.

On a weight basis, silicic acid and Cab-O-Sil were more active than Ludox gel. When normalized on a surface area basis the differences in reaction rates became less pronounced. Therefore, it is very likely that the high per weight activities of silicic acid and Cab-O-Sil can be attributed to their high surface areas. A similar surface area effect could also explain the relatively high blank activity of empty Vycor glass reactors compared to the quartz reactors. Vycor glass is much more porous than quartz, and consequently, Vycor has a higher surface area.

Because of its high activity on a weight basis and, compared to Cab-O-Sil, low carbon dioxide selectivity silicic acid emerges among the silica compounds as a promising candidate for partial oxidation of methane. Therefore, the overall methane reaction and product formation rates as well as the deactivation behavior of silicic acid are examined more closely in the next part of this work.

\section{Methane activation over silicic acid}

In this segment the apparent activation energies for the overall rate of the methane reaction as well as for the rates of formation of the various products are determined. The deactivation characteristics of silicic acid are also investigated.

The reaction was carried out at a pressure of $585 \mathrm{kPa}$ at temperatures that were randomly selected within the range of $783-893 \mathrm{~K}$. Fig. 4 shows the Arrhenius plots for the overall rate of methane reaction as well as for the rates of formation of ethene, formaldehyde, carbon monoxide and carbon dioxide. Very good linear fit of the Arrhenius plots was achieved with squared correlation coefficients from 0.984 to 0.9933 excluding therefore the possibility of substantial catalyst deactivation from one run to the next. 


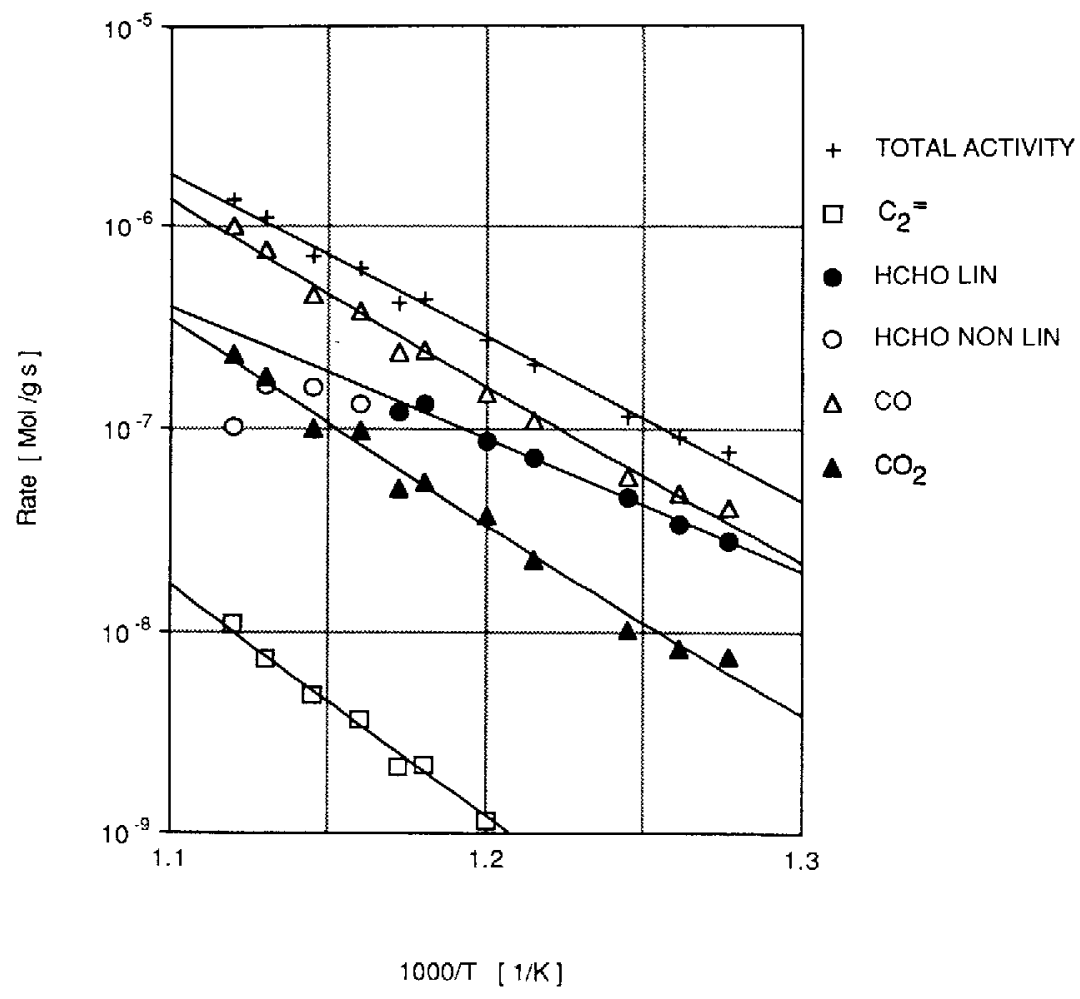

Fig. 4. Arrhenius plots for silicic acid at $585 \mathrm{kPa}$ and $783-893 \mathrm{~K}$. Flow-rates: $10 \%$ methane in argon $=39.8 \mathrm{~cm}^{3} \mathrm{STP} / \mathrm{min}$, oxygen $=4 \mathrm{~cm}^{3} \mathrm{STP} / \mathrm{min}$. The plot for formaldehyde formation is divided into a linear (HCHO LIN) and a nonlinear portion (HCHO NONLIN).

In the case of formaldehyde, however, at temperatures higher than $853 \mathrm{~K} \mathrm{a}$ deviation from linearity was observed in the Arrhenius plot. This deviation from linearity can be attributed to secondary reactions of formaldehyde to carbon monoxide and carbon dioxide. At lower pressures and over the same temperature range of 783 to $893 \mathrm{~K}$ lower rates of formaldehyde formation were obtained without deviations from linearity. The apparent activation energies for the overall rate of methane reaction and the formation of the various products are summarized in Table 4. For comparison, the apparent activation energy values for methane oxidation in empty Vycor glass tubes (based on the data presented in Table 1) were also determined and are included in this table. For Vycor the squared correlation coefficients ranged from 0.9866 to 0.9982 , except for the carbon dioxide rate, where the data points showed a pronounced downward curvature with increasing temperature. As error limits for the apparent activation energy values, the $95 \%$ confidence intervals are given in $\mathrm{Ta}$ ble 4 .

The apparent activation energies over silicic acid were generally lower than 


\section{TABLE 4}

Apparent activation energies for the rate of methane reaction and rates of product formation over silicic acid (at $585 \mathrm{kPa}, 783-893 \mathrm{~K}$ ) and Vycor glass (at $205 \mathrm{kPa}, 893-993 \mathrm{~K}$ )

\begin{tabular}{lll}
\hline & $\begin{array}{l}\text { Silicic acid } \\
(\mathrm{kJ} / \mathrm{mol})\end{array}$ & $\begin{array}{l}\text { Vycor glass } \\
(\mathrm{kJ} / \mathrm{mol})\end{array}$ \\
\hline${\text { Overall } \mathrm{CH}_{4} \text { Reaction }}_{\mathrm{C}_{2} \mathrm{H}_{4}}$ & $154 \pm 10$ & $217 \pm 49$ \\
$\mathrm{C}_{2} \mathrm{H}_{6}$ & $213 \pm 18$ & $299 \pm 39$ \\
$\mathrm{HCHO}$ & (not formed) & $236 \pm 59$ \\
$\mathrm{CO}$ & $125 \pm 15$ (linear portion of plot) & $123 \pm 19$ \\
$\mathrm{CO}_{2}$ & $171 \pm 15$ & $264 \pm 34$ \\
& $184 \pm 18$ & (non linear) \\
\hline
\end{tabular}

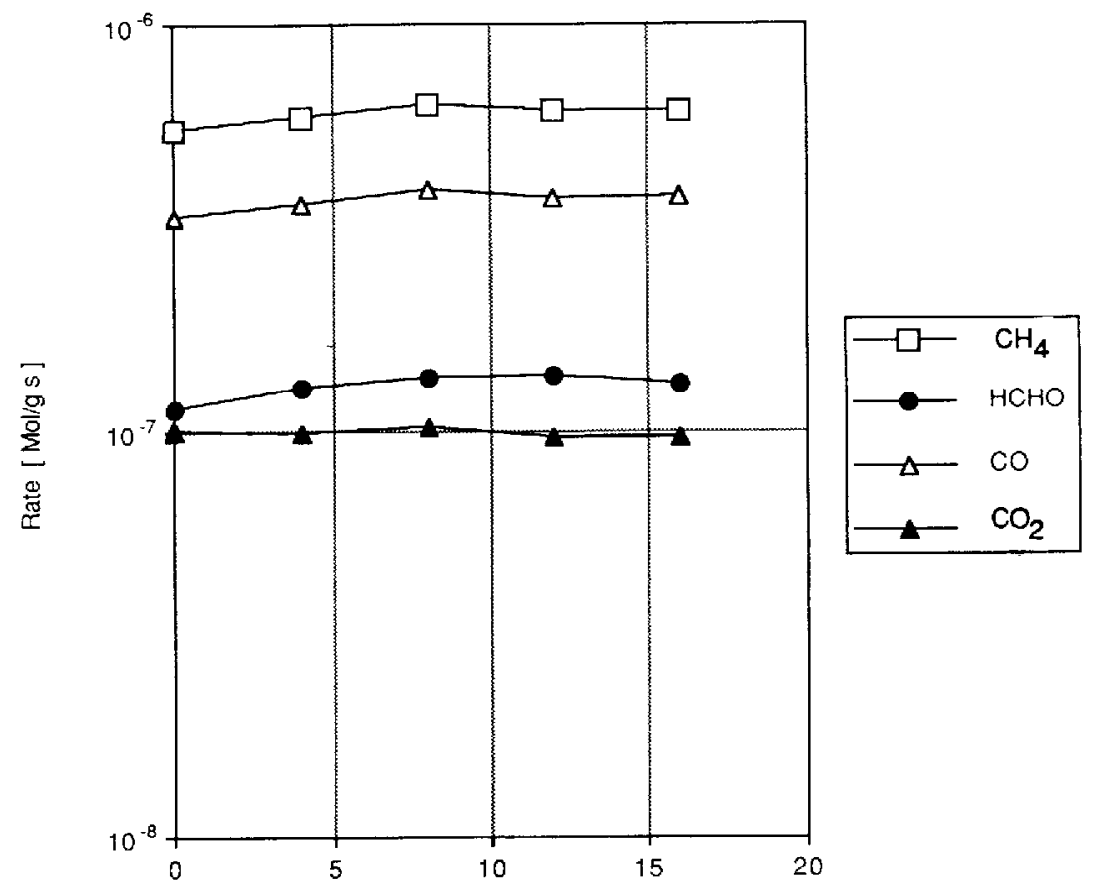

Time on stream [hr]

Fig. 5. Activity maintenance of silicic acid at $585 \mathrm{kPa}$ and $863 \mathrm{~K}$. Flow-rates: $10 \%$ methane in argon $=39.8 \mathrm{~cm}^{3} \mathrm{STP} / \mathrm{min}$, oxygen $=4 \mathrm{~cm}^{3} \mathrm{STP} / \mathrm{min}$.

those over Vycor glass. On both silicic acid and Vycor glass, the apparent activation energy values for formaldehyde were very low and had within experimental error the same value. This might be a first indication that the formation 
of formaldehyde is not very sensitive to the nature of the catalytic surface and one might infer that formaldehyde formation involves a gas phase mechanism. One has to keep in mind that the activation energies presented here are only apparent ones, resulting from a complex interplay of gas phase and surface reactions.

In view of the complexity of these interactions and the many open questions about the reaction mechanisms, it is not yet possible to determine reaction orders and calculate the true activation energies. The difference in the activation energy for carbon monoxide, however, suggests that the subsequent oxidation and/or decomposition of formaldehyde is sensitive to the nature of the catalytic surface or reactor walls.

The activity maintenance was investigated by placing the catalyst on stream after the standard oxygen pretreatment and monitoring its methane oxidation activity for a period of $16 \mathrm{~h}$ at $863 \mathrm{~K}$. As illustrated in Fig. 5 , silicic acid showed excellent activity maintenance. 'The other silicas investigated followed the same behavior.

\section{Effect of calalyst ucidily}

In order to investigate the effect of catalyst acidity on methane oxidation, $\gamma$ $\mathrm{Al}_{2} \mathrm{O}_{3}$ and $\mathrm{MgO}$ were chosen for a comparison with silicic acid [31].

\section{TABLE 5}

Comparison of activities of $\mathrm{MgO}, \gamma-\mathrm{Al}_{2} \mathrm{O}_{3}$ and silicic acid

\begin{tabular}{|c|c|c|c|c|c|c|}
\hline \multirow[t]{2}{*}{ Compound } & \multirow[t]{2}{*}{$p(\mathrm{kPa})$} & \multirow[t]{2}{*}{$T(\mathrm{~K})$} & \multicolumn{4}{|c|}{ rates $(\mathrm{mol} / \mathrm{g}-\mathrm{s})$} \\
\hline & & & $\mathrm{CH}_{4}$ & $\mathrm{CO}$ & $\mathrm{CO}_{2}$ & $\mathrm{HCHO}$ \\
\hline \multirow{3}{*}{$\begin{array}{l}\mathrm{MgO}^{\star} \\
\left(\mathrm{S} . \mathrm{A} .=47 \mathrm{~m}^{2} / \mathrm{g}\right)\end{array}$} & \multirow[t]{3}{*}{205} & 810 & $0.564 \mathrm{E}-6^{8}$ & $0.360 \mathrm{E}-6$ & $0.204 \mathrm{E}-6$ & - \\
\hline & & 853 & $1.439 \mathrm{E}-6$ & $0.810 \mathrm{E}-6$ & $0.629 \mathrm{E}-6$ & - \\
\hline & & 899 & $3.126 \mathrm{~F}-6$ & $1.456 \mathrm{E}-6$ & $1.670 \mathrm{E}-6$ & - \\
\hline \multirow{4}{*}{$\begin{array}{l}?-\mathrm{Al}_{2} \mathrm{O}_{: 3}{ }^{\star *} \\
\left(\text { S.A. }=120 \mathrm{~m}^{2} / \mathrm{g}\right)\end{array}$} & \multirow[t]{4}{*}{294} & 803 & $0.114 \mathrm{E}-6$ & $0.083 \mathrm{E}-6$ & $0.031 \mathrm{E}-6$ & - \\
\hline & & 823 & $0.182 \mathrm{E}-6$ & $0.127 \mathrm{E}-6$ & $0.055 \mathrm{E}-6$ & - \\
\hline & & 853 & $0.430 \mathbf{E}-6$ & $0.273 \mathrm{E}-6$ & $0.157 \mathbf{E}-6$ & - \\
\hline & & 893 & $1.150 \mathrm{E}-6$ & $0.570 \mathrm{E}-6$ & $0.580 \mathrm{E}-6$ & - \\
\hline \multirow{5}{*}{$\begin{array}{l}\text { Silicic acid }{ }^{\star \star} \\
\left(\text { S.A. }=275 \mathrm{~m}^{2} / \mathrm{g}\right)\end{array}$} & \multirow[t]{5}{*}{380} & 833 & $0.621 \mathrm{E}-7$ & $0.330 \mathrm{E}-7$ & $0.086 \mathrm{E}-7$ & $0.205 \mathrm{E}-7$ \\
\hline & & 848 & $0.927 \mathrm{E}-7$ & $0.510 \mathrm{E}-7$ & $0.133 \mathrm{E}-7$ & $0.284 \mathrm{E}-7$ \\
\hline & & 863 & $0.143 \mathrm{E}-6$ & $0.803 \mathrm{E}-7$ & $0.163 \mathrm{E}-7$ & $0.460 \mathrm{E}-7$ \\
\hline & & 883 & $0.245 \mathrm{E}-6$ & $0.149 \mathrm{E}-6$ & $0.295 \mathrm{E}-7$ & $0.660 \mathrm{E}-7$ \\
\hline & & 893 & $0.290 \mathrm{E}-6$ & $0.183 \mathrm{E}-6$ & $0.337 \mathrm{E}-7$ & $0.720 \mathrm{E}-7$ \\
\hline
\end{tabular}

\footnotetext{
"Flow-rates: $10 \%$ methane in argon $=29.6 \mathrm{~cm}^{3} \mathrm{STP} / \mathrm{min}$, oxygen $=3 \mathrm{~cm}^{3} \mathrm{STP} / \mathrm{min}$.

${ }^{\star}$ Flow-rates: $10 \%$ methane in argon $=29.6 \mathrm{~cm}^{3} \mathrm{STP} / \mathrm{min}$, oxygen $=30.9 \mathrm{~cm}^{3} \mathrm{STP} / \mathrm{min}$.

$\star \star \star$ Flow-rates: $10 \%$ methane in argon $=29.6 \mathrm{~cm}^{3} \mathrm{STP} / \mathrm{min}$, oxygen $=3 \mathrm{~cm}^{3} \mathrm{STP} /$ min. Ethene formation rates not shown.

${ }^{8} 0.564 \mathrm{E}-6$ corresponds to $0.564 \cdot 10^{-6}$.
} 


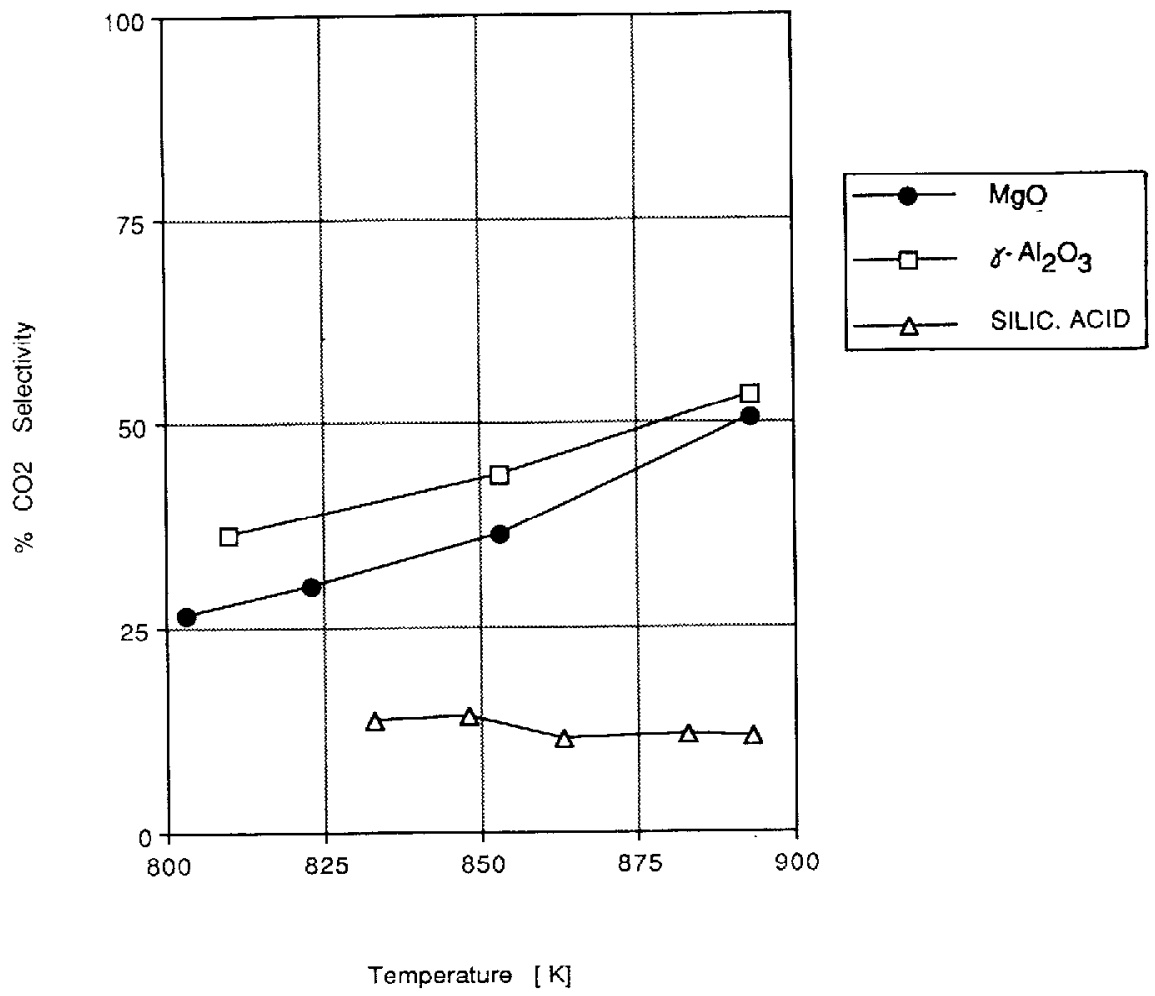

Fig. 6. Carbon dioxide selectivity over $\mathrm{MgO}, \gamma-\mathrm{Al}_{2} \mathrm{O}_{3}$, and silicic acid as a function of temperature (based on data and reaction conditions given in Table 5 ).

Table 5 compares the rates of the overall methane reaction as well as the rates of formation of carbon dioxide and carbon monoxide over $\mathrm{MgO}, \gamma-\mathrm{Al}_{2} \mathrm{O}_{3}$ and silicic acid.

The basic $\mathrm{MgO}$ was the most active catalyst giving carbon monoxide and carbon dioxide as main products. $\gamma-\mathrm{Al}_{2} \mathrm{O}_{3}$ also produced exclusively carbon monoxide and carbon dioxide, however, with lower rates than $\mathrm{MgO}$, even when low methane-to-oxygen ratios were used which should lead to increased reaction rates (Fig. 2). Under our reaction conditions, only the silica based materials including silicic acid produced formaldehyde; the overall rate of methane reaction over silicic acid, however, was low compared to that over $\gamma-\mathrm{Al}_{2} \mathrm{O}_{3}$ and $\mathrm{MgO}$, despite the higher pressure used in the experiments with silicic acid. Let us recall here that higher pressure increases the overall rate of reaction (Table 3 ). The activity trends emerging from Table 5 are enhanced even further when the rates are normalized per surface area rather than per weight.

The general conclusion is that $\gamma-\mathrm{Al}_{2} \mathrm{O}_{3}$ is less active than $\mathrm{MgO}$. Both types of oxide surfaces, however, do not seem to preserve formaldehyde, yielding 
instead deep oxidation products carbon monoxide and carbon dioxide. Formaldehyde is only produced over the moderately acidic silicic acid. These results seem to agree in principle with exchange reaction studies between $\mathrm{C}^{2} \mathrm{H}_{4}$ and methane performed by Quanzhi and Amenomiya [32] where it was found that $\gamma-\mathrm{Al}_{2} \mathrm{O}_{3}$ and $\mathrm{MgO}$ were the most active catalysts, whereas $\mathrm{SiO}_{2}$ was completely inactive up to $873 \mathrm{~K}$. Larson and Hall [33] in a previous study have concluded that the exchange reaction can take place more readily on alumina than on more acidic silica-alumina catalysts.

An important trend pertains to the carbon dioxide selectivity as a function of temperature (Fig. 6). In the case of $\gamma-\mathrm{Al}_{2} \mathrm{O}_{3}$ and $\mathrm{MgO}$, the carbon dioxide selectivity increases with temperature and almost doubles over the range of 793 to $893 \mathrm{~K}$. In the case of silicic acid, however, the carbon dioxide selectivity remains almost unchanged at 10 to $13 \%$.

Furthermore, the carbon dioxide selectivity does not appear to significantly change with pressure, as shown in Table 3 . As a consequence, silicic acid appears to be very promising for the conversion of methane into products other than carbon dioxide.

\section{CONCLUSIONS AND RECOMMENDATIONS}

It is proposed that formaldehyde, ethane and ethene can be produced by the selective oxidation of methane involving interactions with the walls of Vycor brand glass and quartz glass tubes. The residence time and the methane-tooxygen ratio play critical roles in the activity and selectivity. Reaction mixtures rich in oxygen favor high conversions of methane and high yields of carbon monoxide. It appears that formaldehyde is a primary product while carbon monoxide and carbon dioxide are, at least in part, secondary products of formaldehyde oxidation. However, at the high temperatures used it is likely that gas phase combustion reactions (chain initiation, propagation and termination ) may be taking place as well. The exact contribution of gas-phase reactions to the observed activity and selectivity towards useful intermediate products is yet to be elucidated.

Similar activity and selectivity trends were observed over various silica compounds implying that probably the silica in the glass and not impurities are responsible for the activity. Although the elucidation of the mechanism of the reaction is beyond the scope of this particular publication it seems very likely that the generation of the $\mathrm{CH}_{3} \cdot$ radicals occurs via the interaction of methane molecules with the silica surface. It cannot be excluded that surface hydroxyl groups are involved in the process, facilitating the loss of a hydrogen atom from methane via hydrogen bond interactions. Subsequent oxidation of the radicals may involve a complex sequence of surface and gas-phase reactions. The effect of the amount of ethane impurities in the feed stream needs to be investigated 
as well, since it is quite possible that ethane can act as an initiator of $\mathrm{CH}_{3} \cdot$ radical formation.

$\mathrm{MgO}$ and $\gamma-\mathrm{Al}_{2} \mathrm{O}_{3}$ are more active than the silica compounds but they only form carbon dioxide and carbon monoxide. Therefore, moderate acidity seems to favor the selectivity towards formaldehyde.

The formaldehyde production of the silica compounds can be enhanced under low residence times, high pressures and low methane-to-oxygen ratios. High surface area compounds were more active on a per unit weight basis, however, the differences were not as pronounced when the activity was normalized on a per surface area basis. The surface area is therefore an important factor in the activity and selectivity and this could explain the high yields obtained over the porous Vycor brand U-tubes compared to the less porous quartz reactors.

The uniformly low apparent activation energy for formaldehyde formation observed for all the silica catalysts and for the Vycor and quartz tubes implies that formaldehyde may be a primary product of gas phase reaction of $\mathrm{CH}_{x} \cdot$ radicals generated on the surface. The subsequent decomposition and/or oxidation of formaldehyde to carbon monoxide and carbon dioxide appears to be sensitive to the nature of the surface.

The overall picture emerging is that of a rather complex set of surface and gas phase reactions, with variables such as residence time and probably also reactor geometry coming into play. Traditional heterogeneous reaction engineering does not seem to be fully applicable to deal with this situation, and a much larger database needs to be established before meaningful mechanistic and kinetic modelling comes within reach. Optimization of a catalytic surface alone will not hold the key to successful activation of methane for large scale technological applications. The interplay between surface catalysis, wall reactions, homogeneous gas phase and radical reactions needs to be studied in great detail in order to achieve the desired high methane conversions while maintaining favorable selectivities for partial oxidation products.

\section{ACKNOWLEDGEMENTS}

Final support of this work through the Gas Research Institute under GRI Contract 5086-260-1324 is gratefully acknowledged.

\section{REFERENCES}

1 R. Pitchai and K. Klier, Catal. Rev.-Sci. Eng., 28 (1986) 13.

2 C\&E News, (June 1, 1987) 22.

3 G.E. Keller and M.M. Bhasin, J. Catal., 73 (1982) 9.

4 T. Ito, J.-X. Wang, C.-H. Lin and J.H. Lunsford, J. Am. Chem. Soc., 107 (1985) 5062.

5 K. Otsuka, K. Jinno and A. Morikawa, J. Catal., 100 (1986) 353.

6 C.-H. Lin, K.D. Campbell, J.-X. Wang and J.H. Lunsford, J. Phys. Chem., 90 (1986) 534. 
7 J.A. Sofranko, J.J. Leonard and C.A. Jones, J. Catal., 103 (1987) 302.

8 C.A. Jones, J.J. Leonard, and J.A. Sofranko, J. Catal., 103 (1987) 311.

9 T.A. Emesh and Y. Amenomiya, J. Phys. Chem., 90 (1986) 4785.

10 D.J. Hucknall, Chemistry of Hydrocarbon Combustion, Chapman and Hall, New York, 1985.

11 C\&E News, (April 20, 1987) 10.

12 Kirk-Othmer, Encyclopedia of Chemical Technology, Wiley, New York, 1981, 3rd ed., p. 13.

13 C.D. Chang, J.C.W. Kuo, W.H. Lang, S.M. Jacob, J.J. Wise and A.J. Silvestri, Ind. Eng. Chem. Process Des. Dev., 17 (1978) 255.

14 H.-F. Liu, R.-S. Liu, K.Y. Liew, R.E. Johnson and J.H. Lunsford, J, Am. Chem. Soc., 106 (1984) 4117.

15 M.M. Khan and G.A. Somorjai, J. Catal., 91 (1985) 263.

16 H.D. Gesser, N.R. Hunter and L. Morton, U.S. Patent 4618 732, 21 Oct. 1986.

17 S. Antonik and M. Lucquin, Bull. Soc. Chim. Fr., (1970) 2861.

18 S. Antonik, Bull. Soc. Chim. Fr., 12 (1973) 3296.

19 E.M. Kegeyan, I.A. Vardanyan and A.B. Nalbandyan, Kin. Katal., 17 (1976) 856.

20 E.M. Kegeyan, I.A. Vardanyan and A.B. Nalbandyan, Kin. Katal., 17 (1976) 862.

21 B.H. McConkey and P.R. Wilkinson, Ind. Fng. Chem. Process Des. Dev., 6 (1967) 255.

22 L.H. Little, H.E. Klauser and C.H. Amberg, Can. J. Chem., 39 (1961) 42.

23 N.W. Cant and L.H. Little, Can. J. Chem., 42 (1964) 802.

24 M. Folman and D.J.C. Yates, Proc. Roy, Soc. London, A 246 (1958) 32.

25 L.H. Little, Infrared Spectra of Adsorbed Species, Academic Press, New York, 1966, pp. 229267.

26 N. Sheppard and D.J.C. Yates, Proc. Roy. Soc. London, A 238 (1956) 69.

27 D.E. Cheaney and A.. Walsh, Fuel, 35 (1956) 238.

28 W. Grabowski, J. Mol. Catal., $3(1977 / 78) 299$.

29 L.T. Thompson, Ph.D. Thesis, The University of Michigan, 1986.

30 M.E. Nordberg, J. Am. Ceram. Soc., 27 (1944) 299.

31 K. Tanabe, Solid Acids and Bases, Their Catalytic Properties, Academic Press, New York, 1970.

32 L.I. Quanzhi and Y. Amenomiya, Appl. Catal., 23 (1986) 173.

33 J.G. Larson and W.K. Hall, J. Phys. Chem., 69 (1965) 3080. 